\title{
Improving the Mechanical Properties of Fiber Metal Laminate Composite Used in Aircraft Wing
}

\author{
Ahmed M. Kadhum ${ }^{1}$, Ali A. Al-katawy ${ }^{2}$, Saad T. Faris ${ }^{3}$, Ehklas E. Kader ${ }^{3}$
}

\begin{abstract}
Authors affiliations:
$\left.1^{*}\right)$ M.Sc. Student, Mechanical Eng. Dep., Daiyla University Baquba City, Daiyla, Iraq. ahmedkadum9119@gmail.com

2) Materials Eng. Dep., Daiyla University - Baquba City, Daiyla, Iraq.

Al-katawy@yahoo.com

3) Mechanical Eng. Dep., Daiyla University - Baquba City, Daiyla, Iraq.
\end{abstract}

\section{Paper History:}

Received: $5^{\text {nd }}$ Oct. 2018

Revised: $27^{\text {th }}$ Dec. 2018

Accepted: 30th Jan. 2019
Abstract

The purpose of this study is to reduce weight and improve the mechanical properties of aircraft wing using Hybrid materials known as fiber metal laminates (FMLs). In this study, seven layers were used to produce the FMLs that consist of aluminum alloy2024-T3 reinforced by carbon and glass fibers bonded with blend of epoxy-resole. The Carbon Glass Reinforced Aluminum Laminates (CAGRALLs) was used as FMLs. The results showed that The CAGRALLs gave good mechanical properties because of increasing in tensile strength, elongation at fracture and impact toughness except flexural strength by comparing with other FMLs using commercial epoxy. The increasing in layers led to weaken adhesion force between layers of FMLs caused decreasing almost mechanical properties. The FMLs has good mechanical properties by using carbon and glass fibers by comparing with carbon and jute fibers. The CAGRALLs have higher numbers of cycles at failure under cyclic loadings than Aramid Reinforced Aluminum Laminates (ARALLs). The CAGRALLs have lower density by comparing with aluminum alloy 2024T3 that used in manufacturing of aircraft wing.

Keywords: Fiber Metal Laminate Composite, Mechanical Properties, Hybrid Composite Materials.

$$
\begin{aligned}
& \text { تحسين الخصائص الميكانيكية للمادة المتراككة المتعددة الطبقات المستخدمة في جناح } \\
& \text { الطائرة } \\
& \text { احمد محم كاظم ، ، علي عدوان الخطاوي، سعد ذياب فارس3، اخلاص عيدان قادر3 }
\end{aligned}
$$

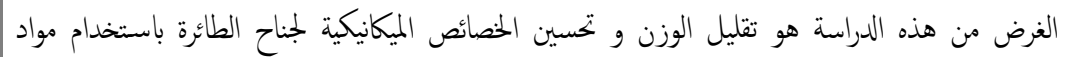

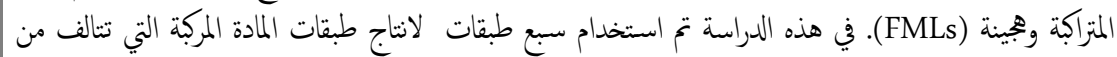

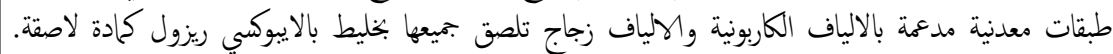

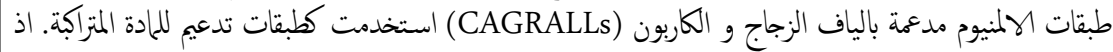

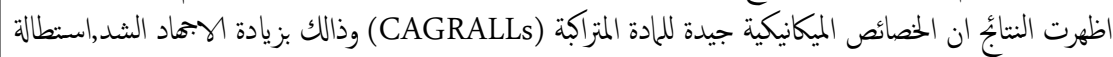

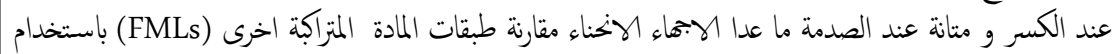

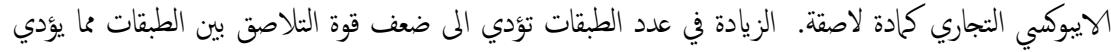

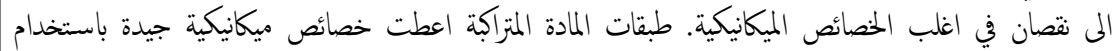

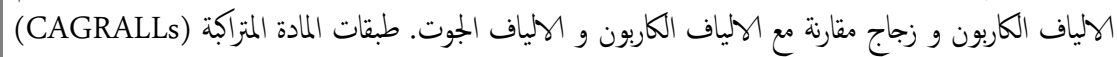

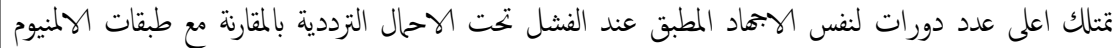

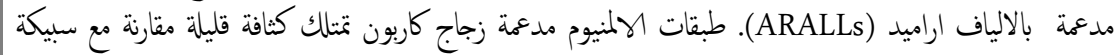
الكمنيوم (T3-2024) المستخدمة في صناعة جناح الطائرة.

\section{Introduction}

Advanced composite materials were manufactured from reinforcement materials embedded with matrix phase. They have improved in the material properties such as strength and stiffness by laminating the fibers orientated in different directions. Fibers are supported and bonded together in the composite materials by a matrix resin. It has

NJES is an open access Journal with ISSN 2521-9154 and eISSN 2521-9162

This work is licensed under a Creative Commons Attribution-NonCommercial 4.0 International License 
ability to transfer the applied loads to fibers that keep their position, which gives good resistance of environment for the composites [1]. The FMLs are the group of engineering materials, which consist of Polymer Matrix Composites (PMC) embedded with metal foils (as shown in fig.1 [4]). They are capable for withstanding high temperature, aggressive environment and resisting oxidation and moisture ingress [2]. With designed based on beneficial of different properties of the fibers employed. For example, the mixing of glass fiber with carbon fiber embedded within a polymer matrix gives inexpensive composite because the glass fibers have low cost but with mechanical properties enhanced by the excellent stiffness of carbon [3].

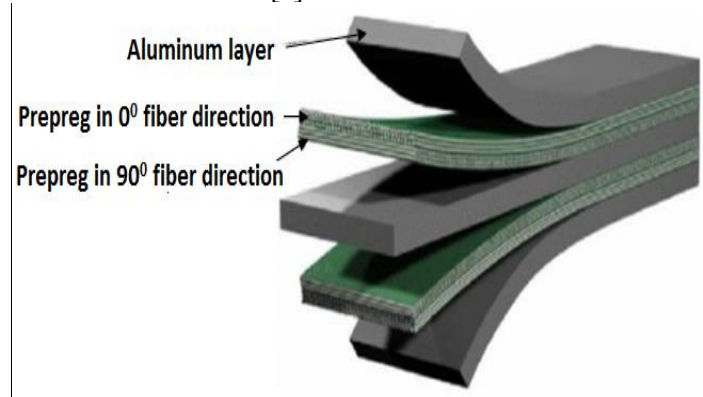

Figure (1): Schematic presentation of FMLs [4]

The impact damage is very important in aerospace structures. There are different damages, which occurred at FMLs like plastic deformation of the metal, delaminating between composite laminates, matrix cracking and fiber failure and loss adhesion between the metal and composite layers [5]. The aircraft structure parts are made of both composite materials and metals. The wing structure is carried some of heavier loads that affect in the aircraft structure. The design of aircraft wing depends on many factors like the size, weight, speed rate of climb and use of the aircraft [6]. The Glass Reinforced Aluminum Laminates (GLARE) was the first type of FMLs, which used in Airbus A380 super jumbo in 2001 [7]. Phenolic materials are both acid (novolac) and base (resole) catalyzed used in production of composites. They used as matrices in these applications to protect and support reinforced fibers contained within composite structure. They have low fire, smoke and toxicity properties [8]. Production of resole has achieved by the alkaline reaction of formaldehyde with phenol or phenol derivative under basic catalyst like $\mathrm{NaOH}$, Calisuin oxide, etc. The molar ratio of formaldehyde to phenol $(\mathrm{F} / \mathrm{P})$ is from 1:1 to $3: 1$. The resole is mono or poly-nuclear hydroxyl-methyl phenols (HMP) which is stable at room temperature but add heat and seldom acids that has transformed into three dimensionally cross-liked insoluble and infusible polymers over different stages. The resole not need hardener to cure because the hardening process of resole has the heat curing [9]. Chlupová,et al were studied the fatigue crack growth of the GLARE [10]. Vasumathi et al studied the mechanical properties of Carbon Jute Reinforced Aluminum Laminates (CAJRALL) The young's modulus, flexural strength, flexural modulus and impact toughness were decreases with increasing number of layers. [11]. Rajkumar et al studied the tensile and flexural of FMLs. The aluminum and carbon fiber reinforced plastics had better bonding that lead to arrest the crack in the flexural test [12]. Harichandan, A., and et al., studied the tensile behavior of CAJALL [13].

In the present study, the mechanical properties (namely as: tensile, flexural, impact and fatigue) of CAGRALLs have been evaluated and studied that used in aircraft wings. The CAGRALLs made of aluminum sheets reinforced by carbon and glass fibers have been bonded using epoxy-resole.

\section{Experimental Works:}

\subsection{Materials}

In this study, the fabrication of FMLs has been carried out by carbon and glass fibers as well as the blend of epoxy-novolac as matrix were used. The aluminum sheets have been used as FMLs plate. The CAGRALLs as FMLs have been fabricated from three sheets of aluminum alloy 2024-T3 $(0.5 \mathrm{~mm}$ thick) reinforced by carbon fiber SikaWrap-301C, EGlass fiber EWR450 and epoxy Sikadur 52 resin with its hardener and resole resin as adhesion between layers. The properties of resins are presented in Tables $1 \& 2$. These fibers have purchased from local market and their properties can be presented in Table 3. Aluminum sheets have purchased from Amazon website. The properties and chemical composition of Aluminum sheets can be showed in Tables 4\& 5 respectively. Resole resin was produced by reaction between formaldehyde and phenol under base $\mathrm{PH}$ conditions with excess formaldehyde that led to the molar formaldehyde to phenol ratio greater than one (>1) [14]. Resole resin is produced locally from That Al-Sawary Company /Baghdad/Al-taji in Iraq. Aluminum alloy 2024-T3 has high strength to weight ratio as well as good fatigue resistance [15]. The Hand layup technique is used to produce of FMLs for this work at room temperature. Fibers and Aluminum sheets cut according to the desired size and held in the mould. The pressing by roller has applied to the skins. The applied pressure compresses the prepreg for improving the bonding between the fibers and aluminum sheets. The time was enough for suitable bonding to occur. The mixing ratio is $90 \%$ of epoxy with $10 \%$ resole resin. The weight fraction $0.2 \mathrm{wt}$ for reinforcement was used in this work. The specimens was consist of seven layers $\left(\mathrm{Al} / \mathrm{C}_{90} / \mathrm{G}_{45} / \mathrm{Al} /\right.$ $\left.\mathrm{G}_{45} / \mathrm{C}_{90} / \mathrm{Al}\right)$ was used in this work. The specimens made to the size $(300 \times 300 \times 3 \mathrm{~mm})$. The $\mathrm{CNC}$ water jet machine is a machine, which used for cutting the hard materials by water jetting. It is used to cut specimens according to ASTM standard for each test. At least two specimens were used in each test (see fig.2).

Table (1): Properties of resins used in this study [16,

\begin{tabular}{|c|c|c|}
\hline 17$]$ & Resole resin \\
\hline Property & $\begin{array}{c}\text { Polyprime-EP } \\
\text { epoxy }\end{array}$ & Nutty \\
\hline $\begin{array}{c}\text { Color } \\
\text { Ciscosity }\end{array}$ & $\begin{array}{c}\text { Amber } \\
\text { for resin and }\end{array}$ & $400-700$ \\
\hline
\end{tabular}




\begin{tabular}{|c|c|c|}
\hline $\begin{array}{c}\text { Density } \\
\mathrm{g} / \mathrm{cm}^{3}\end{array}$ & 1.05 & 1.22 \\
\hline Pot life min & $>3$ & $>20$ \\
\hline $\begin{array}{c}\text { Water } \\
\text { resistance }\end{array}$ & Very good & $\begin{array}{c}\text { Mixing with water } \\
\text { so as not to harden }\end{array}$ \\
\hline
\end{tabular}

Table (2): Properties of fibers used in this study [18, 19]

\begin{tabular}{|c|c|c|}
\hline Property & EWR 450 & SIikawrap301 C \\
\hline Material & E-glass fiber & Carbon fiber \\
\hline Color & white & black \\
\hline Orientation & $\begin{array}{c}45^{\circ} \text { (Woven } \\
\text { Roving) }\end{array}$ & $\begin{array}{c}0^{\circ} \\
\text { (unidirectional) }\end{array}$ \\
\hline Density & $1.88 \mathrm{~g} / \mathrm{cm}^{3}$ & $1.8 \mathrm{~g} / \mathrm{cm}^{3}$ \\
\hline Thickness & $0.3 \mathrm{~mm}$ & $0.17 \mathrm{~mm}$ \\
\hline Tensile strength & $331 \mathrm{MPa}$ & $4900 \mathrm{MPa}$ \\
\hline Elastic modulus & $25.86 \mathrm{GPa}$ & $230 \mathrm{GPa}$ \\
\hline Elongation at break & $3.4 \%$ & $2.1 \%$ \\
\hline
\end{tabular}

Table (3): Properties of Al-alloy used in this study [20]

\begin{tabular}{|c|c|}
\hline Property & Value \\
\hline Density & $2.78 \mathrm{~g} / \mathrm{cm}^{3}$ \\
\hline Tensile strength & $435 \mathrm{MPa}$ \\
\hline Yield strength & $290 \mathrm{MPa}$ \\
\hline Elongation & $10-15 \%$ \\
\hline Endurance limit & $138 \mathrm{Mpa}$ \\
\hline Elastic modulus & $73.1 \mathrm{GPa}$ \\
\hline Poisson's ratio & 0.33 \\
\hline
\end{tabular}

Table (4): Chemical compositions of AL-alloy used in this study [20]

\begin{tabular}{|c|c|}
\hline Component & Wt. $\%$ \\
\hline $\mathrm{Cr}$ & 0.1 \\
\hline $\mathrm{Cu}$ & $3.8-4.9$ \\
\hline $\mathrm{Fe}$ & 0.5 \\
\hline $\mathrm{Mg}$ & $1.2-1.8$ \\
\hline $\mathrm{Mn}$ & $0.3-0.9$ \\
\hline $\mathrm{Si}$ & 0.5 \\
\hline $\mathrm{Ti}$ & 0.15 \\
\hline $\mathrm{Zn}$ & 0.25 \\
\hline Other each & 0.05 \\
\hline Other total & 0.15 \\
\hline $\mathrm{Al}$ & Reminder \\
\hline
\end{tabular}

\subsection{Mechanical tests}

The tensile test specimen was prepared according to the standard ASTM D-638(Universal Testing Machine/model wdw_50/ Laryee Technology Company, China, 2012). The tensile test was carried out in the University of Technology/ Materials Engineering/in the materials strengths laboratory. The shape of the tensile test specimens is a dog bone, as shown in fig.2a. The flexural test specimen was prepared according to the standard ASTM D790 (Universal Testing Machine/model CZL203-2000kg/ Dongguan Jianqiao Testing Equipment Co., Ltd., China, 2005). The flexural test was carried out in the University of Technology /Applied Science Department / the strength of materials laboratory. The three points flexural test was used in this study since the most common test method used in composites. The charpy impact test with V-notch was used. The specimen was prepared according to the standard ISO 179 (Pendulum impact
tester/PSW 750, Zwick Roell Materials Testing, Germany, 2007). The impact test was carried out in the General Company for Engineering Inspection and Rehabilitation. The Fatigue test was carried out using a rotating cantilever load at the end. The specimen was prepared according to standard HSM 20 Rotating fatigue (alternating bending fatigue machine /model HSM20, Hi-Tech Ltd. UK., 2001). The fatigue test was carried out in the Al-Nahrain University / college of Engineering/mechanical department in the applied mechanics laboratory. These tests are done at room laboratory temperature. Figure 2 shows shapes and dimensions of specimens for each test.

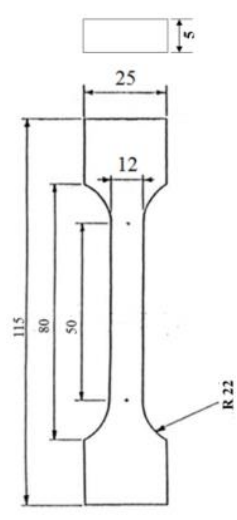

(a) For tensile test

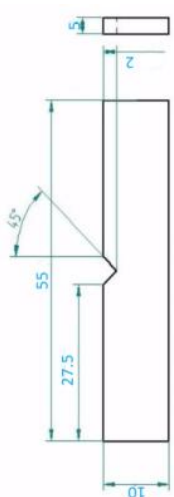

(c) For impact test

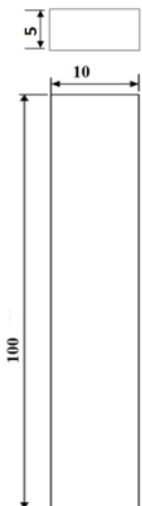

(b) For flexural test

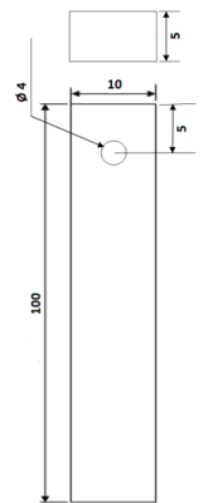

(d) For fatigue test
Figure (2): Schematic illustration of experimental laminates for CAGRALLs (All dimensions in $\mathrm{mm}$.)

\section{Results and Discussion}

In the present research, Aluminum alloy (2024T3) was reinforced with carbon and glass fibers bonded by Epoxy-Resole as matrix phase.

Figure 3 shows the stress-strain curve of CAGRALLs. The figure indicated that the tensile load carrying capacity increased up to certain extends and after that, there was sudden fall at increasing load. Rajkumar et al [12], used four sheets from aluminum reinforced by four carbon and two glass fibers bonded using epoxy (CACAGRALLs) and obtained that tensile strength (200 MPa) was lower to CAGRALLs $(247 \mathrm{MPa})$ because of increasing in layers led to decrease the tensile strength (see fig.4). Rajkumar et al [12], obtained that elongation at fracture $(8.5 \%)$ was lower than CAGRALLs (20.45\%). Aluminum alloy 2024-T3 has maximum elongation $15 \%$. We note that CAGRALLs using 
epoxy-resole have higher by comparing with FMLs using epoxy and aluminum.

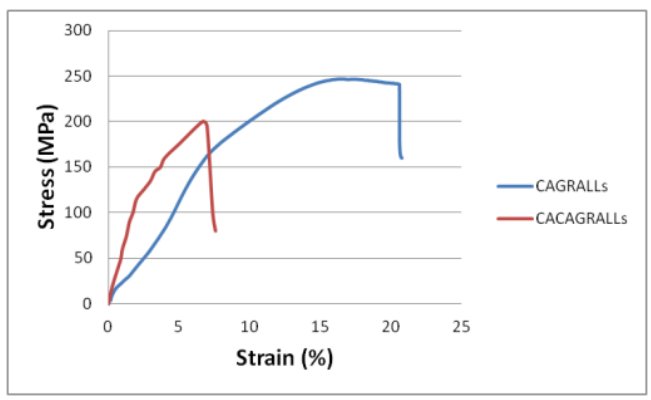

Figure (3): Stress-strain curve for CAGRALLs

Rajkumar et al [12] obtained the flexural strength $(320 \mathrm{MPa})$ is higher than CAGRALLs $(255.15 \mathrm{MPa})$ because of increasing in layers led to increase the flexural strength (see fig.4). It indicates that epoxyresole adhesion was better than epoxy for CAGRALL. The flexural test was applied to the combined stresses: the pressure stress is in the outer surface and the shear stress occurred in inner surface [21]. Results show that the shear strength of about 17 MPa for CAGRALLs.

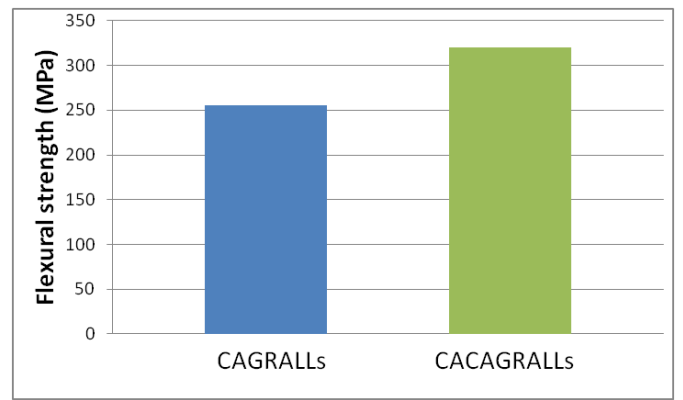

Figure (4): Flexural strength values for FMLs

Vasumathi et al [11] used seven aluminum sheets reinforced by five layers of carbon and jute fiber bonded using epoxy (CAJURALLs) and obtained the impact toughness $\left(23.2410^{-4} \mathrm{~J} / \mathrm{mm}^{3}\right)$ is lower than CAGRALLs $\left(3510^{-4} \mathrm{~J} / \mathrm{mm}^{3}\right)$ because of increasing in layers led to decrease impact toughness. We note that carbon with jute fibers led to have the low impact toughness by comparing with using carbon with glass fibers (see fig.5).

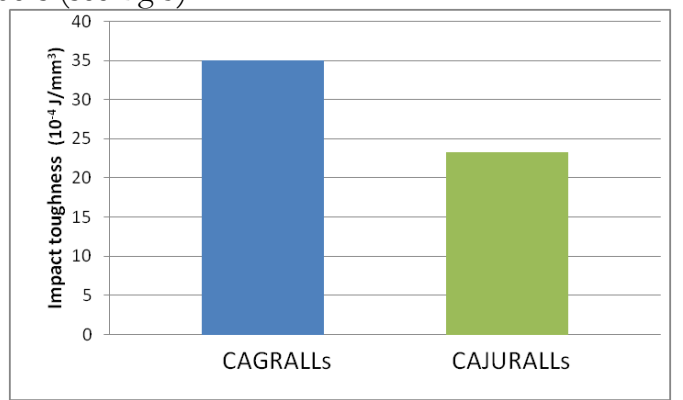

Figure (5): Impact toughness values for FMLs

Figure 6 shows the number of life for CAGRALLs under the fluctuating stresses applied lead to failure. In this work a range of stresses $(\mathrm{R}=$ 1) were used. At reversed stress (100 MPa), the number of cycles at failure were obtained of about $2.86 \times 10^{4}$ cycles. At reversed stress $200 \mathrm{MPa}$, the number of life cycles were obtained about $5.758 \times 10^{3}$ cycles for CAGRALLs. Chulpova A. et al [10], used The GLARE $3 / 2$ lay-up has unidirectional fiber. The range of stress $(R=0.04)$ was used. The number of life for GLARE under stresses applied that lead to failure can be showed in fig.6 [10]. The GLARE has high number of cycles with using epoxy by comparing with CAGRALLs with using epoxy-resole because this blend has more cracks that led to reduce number of cycles (see fig.4). Qaiser et al [22] used aluminum sheet reinforced by Kevlar 49 fiber cloth bonded by epoxy with range of stress $(R=5)$ and obtained that the number of cycles (of about 3000 cycles) was lower to CAGRALLs because of carbon fiber have excellent fatigue resistance comparing with other fibers. Typically, the range of stresses $(\mathrm{R})$ is lower than zero $(\mathrm{R}<0)$ caused low fatigue life for composite materials [23].

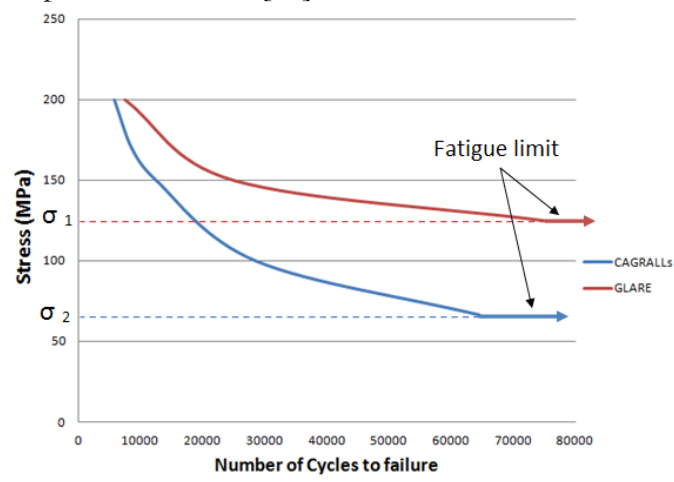

Figure (6): S-N curve for CAGRALLs

The design of wing must be caused decreasing in its weight so that aluminum used more than metals like steel. The density of aluminum is $2.78 \mathrm{~g} / \mathrm{cm} 3$ and steel is $7.86 \mathrm{~g} / \mathrm{cm} 3$ [20].Density has achieved from fabrication of CAGRALLs $\left(2.092 \mathrm{~g} / \mathrm{cm}^{3}\right)$. It indicates that the density of CAGRALLs was lower comparing to aluminum and steel. It is practically calculated. These CAGRALLs have caused low density comparing with Aluminum alloys 2024-T3.

\section{Conclusions}

This study was the first attempt to know and study the changes and improvement of mechanical properties for CAGRALLs, which used in manufacturing of aircraft wing. The tensile strength increased up to certain limit and then fails due to the variation of metal-fiber laminate. The flexural strength also showed the same trend due to three different materials such as two fibers and aluminum. The CAGRALLs has high tensile and elongation at fracture comparing with CACAGRALLs but it has low flexural strength. The CAGRALLs has high impact toughness comparing with CAJURALLs. The CAGRALLs has high elongation comparing to aluminum. The CAGRALLs has low density comparing with aluminum alloy.

\section{Acknowledgment:}

This work was supported by Diayala University, college of Engineering, Mechanical Engineering Department, which is gratefully acknowledged. 


\section{References}

[1] Subramani, M. N. Review on Hybrid Composite Materials and its Applications. International Research Journal of Engineering and Technology (IRJET) 2017.

[2] Ramulu, M., Pahuja, R., Hashish, M., and Isvilonanda, $\mathrm{V}$. Abrasive waterjet machining effects on kerf quality in thin fiber metal laminate. In Proceedings of the 2015 WJTA-IMCA Conference and Expo, 2015.

[3] Matthews, F. L., Davies, G. A. O., Hitchings, D., and Soutis, C.. Finite element modelling of composite materials and structures. Elsevier. Published by Woodhead Publishing Limited, Abington Hall, Abington Cambridge CB1 6AH, England, 2000.

[4] Emberey, C. L., Milton, N. R., Berends, J. P. T. J., Van Tooren, M. J. L., Van der Elst, S. W. G., \& Vermeulen, B. Application of knowledge engineering methodologies to support engineering design application development in aerospace. In 7th AIAA ATIO Conf, 2nd CEIAT Int'l Conf on Innov and Integr in Aero Sciences, 17th LTA Systems Tech Conf; p. 7708, 2007.

[5] Rathnasabapathy, M., Mouritz, A. P., and Orifici, A. C. Numerical investigation of fibre-metal laminates subject to impact damage. In Proceedings of 18th International Conference on Composite Materials, 2011.

[6] Saripalli B., Pandu R., and Vijay John, Vibration and CFD Analysis of Hybrid Composite Wing, International Journal of Novel Research in Electrical and Mechanical Engineering, p.p.105-116, 2015

[7] Sundaravalli S., Majumder, M.C., and Vijayaraghavan G.K, Effect of thermal properties on delaminated fiber metal laminate, International Journal of Emerging Technology and Advanced Engineering, 2012.

[8] Shafizadeh, J. E., and Seferis, J. C., Characterization of phenolic resins for composite honeycomb applications. Society of Manufacturing Engineers, 2000.

[9] Srivastava K., Kumar C., Srivastava D., and Tripathi S. K., Synthesis and characterization of resoles and their blends with epoxy resin : a review, MMAIJ 3(4)176-200, 2007.

[10] Chlupová, A., and Kozák, V. Fatigue crack growth and delamination in fiber metal laminate (GLARE) during loading with positive mean stress. $18^{\text {th }}$ International Conference in Engineering Mechanics, 300, pp. 531-536, 2012.

[11] Vasumathi, M., and Murali, V. Effect of alternate metals for use in natural fibre reinforced fibre metal laminates under bending, impact and axial loadings. International Conference on Design and Manufacturing. Procedia Engineering, 64, 562-570, 2013.
[12] Rajkumar, G. R., Krishna, M., Narasimhamurthy, H. N., Keshavamurthy, Y. C., and Nataraj, J. R. Investigation of tensile and bending behavior of aluminum based hybrid fiber metal laminates. International Conference on Advances in Manufacturing and Materials Engineering (AMME). Procedia Materials Science, 5, pp.60-68, 2014.

[13] Harichandan, A., and Kumar, K. R. V. Study on tensile behaviour of carbon jute aluminium-fibre metal laminates. International journal of mechanical and production engineering, 2016.

[14] Kawamoto, A. M., Pardini, L. C., Diniz, M. F., Lourenço, V. L., and Takahashi, M. F. K. Synthesis of a boron modified phenolic resin. Journal of Aerospace Technology and Management, 2(2) 169182, 2010.

[15] Kulkarni, P. Evaluation of Mechanical Properties of Al 2024 Based Hybrid Metal Composites. IOSR Journal of Mechanical and Civil Engineering (IOSR JMCE), 2015.

[16] Gharkan, M. R., Improvement the Mechanical and Physical Properties of Epoxy-Polyurethane Matrix Resin by Using Kevlar Fiber and $\mathrm{ZnO}$ Particles. Engineering and Technology Journal, 35(3 Part (A) Engineering), 261-266, 2017.

[17] Ismail, I. N., Ishak, Z. A. M., Jaafar, M. F., Omar, S., Zainal Abidin, M. F., and Ahmad Marzuki, H. F., Thermomechanical properties of toughened phenolic resol resin. Solid state science and technology, 17(1), 155-165, 2009.

[18] Astrom, B., Manufacturing of Polymer Composites, Chapman \& Hall, 1997.

[19] Al-Mutairee, H. M., \& Al-Hamdani, H. A., Flexure Behavior of Hybrid Continuous Deep Beam Strengthened by Carbon Fiber Reinforced Polymer. Journal of University of Babylon, 25(5), 1580-1592, 2017.

[20] Metals handbook. 2. Properties and selection: nonferrous alloys and special-purpose materials. American Society for Metals, 1990.

[21] Rijab M. A., Kader E. I., Hamod A. A., Hameed A. H. I., Mechanical properties of silica, graphite and carbon fiber reinforced composites, International Journal of Engineering and Technology (IJET), 9 (5) 3532-35, 2017.

[22] Qaiser, M. H., Umar, S., and Nauman, S.. Development and characterization of fatigue resistant Aramid reinforced aluminium laminates (ARALL) for fatigue Critical aircraft components. In IOP Conference Series: Materials Science and Engineering, 60(1) 2050, 2014, IOP Publishing

[23] Tomblin, J., and Seneviratne, W. Determining the fatigue life of composite aircraft structures using life and load-enhancement factors. Final report, Air Traffic Organization, Washington DC, US, 2011. 